\title{
Nigerianism in Nigerian English: A Reflection of Ethnolinguistic Situation
}

\author{
Olusanmi Babarinde \\ Department of Linguistics, Igbo and Other Nigerian Languages, University of Nigeria, Nsukka, Nigeria \\ Ndubuisi Ahamefula \\ Department of Linguistics, Igbo and Other Nigerian Languages, University of Nigeria, Nsukka, Nigeria
}

\begin{abstract}
The study discusses the structure of Nigerian English with a view to examining the influence of Nigerian indigenous languages on this variety of standard English. Data for the analysis were obtained from twelve respondents selected from each of the three major national languages, namely; Hausa, Igbo and Yoruba. This study was carried out using a case study design. Oral test by reading three different texts, and observation were used as instrument to elicit data. The corpus revealed that interlanguage transfer is a major factor that influences the students in the pronunciation of English words. A number of grammatical issues borne out of mother tongue interference were equally discovered. The prominent roles ascribed to the English language led to the desperation by Nigerians to speak the language to the extent of inclusion of some linguistic forms from different indigenous languages. However, the paper affirms that Nigerianism should not be seen as evidence of weak proficiency in English. Rather, it should be viewed as possible signs of acculturation, and creative tendency that are associated with first language (L1) and/or mother tongue usage.
\end{abstract}

Index Terms —ethnolinguistic, interference, mother-tongue, national language, Nigerianism, second language

\section{INTRODUCTION}

Sociolinguistic scholarly investigations have shown that linguistic and social variables coexist. The extent of their influence varies though universal. It is generally agreed that the progressive expansion of the English language worldwide has made it almost everywhere in the world. Decades after the independence, the language still waxes stronger and has assumed a more important status in Nigeria. In addition to being the medium of social and inter-ethnic communication, English is an official language used to conduct legislative, executive and judicial functions at the three tiers local, state and federal government levels.

As a result of the fundamental role the Nigerian constitution ascribed to English, it becomes more or less indispensable in the lives of people. For instance, proficiency in the language is generally required for admission to tertiary institutions and even primary schools where it is a medium of instruction. Due to its prestigious place among over 500 languages in Nigeria, an individual is considered uneducated if $\mathrm{s} / \mathrm{he}$ cannot converse in English, notwithstanding his competence in his mother tongue or first language. According to Babajide (2001), it becomes a necessity for any Nigerian that wants to be relevant in his socioeconomic and political activities to learn and acquire some appreciable level of English.

Given the adoption of English as second and official language, Nigerians always explore their linguistic resources, largely influenced by mother tongue, to introduce some culture-specific vocabulary items into the English language to express their communicative needs, and this has given rise to a hybrid language such as the Pidgin language or Naija, and Nigerian English which is the concern of this paper. This creativity manifests in coinages that reflect the Nigerian ethno-cultural experience. There is rapid increase in the available lexicon used by Nigerians to express their thought in Nigerian English. This lexicon, which is at variance with the native speakers' lexis, contains different coinages to suit the cultural situation and context of usage. This view is corroborated by Odebunmi (2006) that the socio-cultural diversity that exists between the English (European) people and Nigerians (African) provides an avenue for new lexical items to emerge. Odebunmi further notes that before the emergence of the English language in Nigeria, the Nigerian indigenous languages are used to express innermost thoughts, norms, experiences, and the people's culture and with the advent of English in inter- and intra-ethnic communication, new lexical items are bound to develop.

The concept Nigerianism, according to Jowitt (2000), could be viewed as a variety of English form that incorporates the phonological, grammatical and semantic features of any Nigerian language in its linguistic structure. An occurrence or intrusion of this linguistic form in the utterances of any Nigerian while speaking English, notwithstanding the level of education, is known as mother tongue interference or cross-linguistic influence. Weinreich (1968) views it as a disturbance in language systems of the bilinguals. This linguistic transfer largely occurs unconsciously. Researchers like Jowitt (1991), Bamgbose (1995), Bobda (1995), have affirmed the indispensability of English in a second language situation and have examined the variety differentiation and the use of English in Nigeria but none has seen the mother tongue interference as a form of linguistic creativity. However, this paper views interference as signs of acculturation, 
and creative tendency that are associated with first language user in a bid to express his innermost thoughts that are not captured in the standard English.

Scholars differ in their opinions on the existence of Nigerian English. For Jowitt (2008), this variety exists. He succinctly illustrates the divergent views as "left", "right" and "centre" in reaction to the attitude of scholars to tolerance of learners' errors. Scholars on the left position support Adetugbo (1979a), Kachru (1982) and Odumuh (1987) that Nigerian English exists as by right and it is freely used by the literary scholars in their creative writings. Those who hold the "right" view maintains that the peculiar usage noticed in the Nigerian English does not elevate it to be viewed as standard. The standard variety of a language is always generally acceptable and utilised by the literate section of the speech community. The absence of standard is apparent in the systematic errors noticed in the usage and the lack of institutionalization, in the non-existence of any dictionary embracing its usage (cf. Salami 1968, Adesanoye 1973). The central position is widely adopted by scholars. For them, Nigerian English exists in the usage of the educated Nigerians though its features are not yet codified (Grieve 1966, Banjo 1971, Bamgbose 1982, Jibril 1986, Adegbija 2004, Jowitt 2008). This view suggests why Bamgbose (1998) advocates that its codification and acceptability are the most important requirements.

According to Igboanusi, (2006:490-497) says, "In fact, some Nigerians often claim that they can identify the ethnic origin of a Nigerian based on the peculiarities of his/her speech. While this assertion may not be true in most cases, it is an open recognition of the existence of differences in the English language pronunciation patterns of Nigerians. The present investigation underlies the need for contrastive studies of both ethnic and national/regional varieties of English in order to clearly specify peculiarities and commonalities."

The inexhaustible desires by Nigerians to reduce their communicative needs into language have led to re-expressions to conform to the cultural situation and context of usage. The inability of the English language to adequately express every aspects of Nigerian culture has given rise to improvisation creatively formed from Nigerian English lexis and culture-specific lexical items that depict the Nigerian ethnolinguistic situation. The major objective of this paper is to examine the influence of Nigerian indigenous languages on the standard English in which such interference is seen as a reflex manifestation of linguistic creativity of a bilingual speaker.

\section{EMPIRICAL}

Related studies on the influence of indigenous languages on the English language abound. For instance, Kridalaksana (1985) recorded that there are linguistic interference difficulties students faced in mastering a second language due to their competence in their mother tongue. Interference according to him is noticeable at the phonological, grammatical, lexical, and semantic levels. He noted that in South Sulawesi, there are people who are multilingual because they can speak Buginese and Makassarese as well as English. He found that negative transfer of some linguistic forms of either Buginese or Makassarese to the pronunciation of English are very apparent. According to him at the phonological level, a Buginese speaker realizes these English sounds $/ \theta / / \mathrm{f} /, / \mathrm{z} /, / \mathrm{J} /$, found in words like 'think' $/ \theta \mathrm{ryk} /$ as $/$ ting/, 'of'/ov/ as /op/, 'all' /o:1/ as /al/, 'zoom'/zu:m/ as /sum/, shy / Jai/ as /sai/.

Bennui (2008) carried out a research to describe the problems that Thai students faced with mother tongue interference in the learning of English as a Foreign Language in their communicative functions. The study showed there was a considerable level of first language or mother-tongue intrusion which denotes more negative transfers rather than positive transfers in students' written form of English. This result further shows the different kinds of error manifestation evident in the use of vocabulary, phrases, clauses and sentence structure. The study recommends that teachers lay emphasis on every aspect of L1 interference while teaching students.

\section{METHODOLOGY}

This study is a qualitative research design. The data were elicited from twelve respondents (four from each of the three major national languages) through reading drills. This predisposes the researchers to observe the possible intrusion of extraneous linguistic forms influenced by the respondents' ethno-linguistic background. The readings which were later transcribed were recorded on three different midgets based on the number of languages under consideration. The identified interference was identified, described, explained, and evaluated according to Ellis (1997).

\section{LiNGUISTIC FEATURES OF NigERIAN ENGLISH}

Though there seem to be a lot of similarity in the spoken English of Nigerians, it is appropriate to discuss some areas of dissimilarities in the English pronunciation of Nigerians from different ethnic and linguistic backgrounds. The features that mark Nigerian English are largely within the core linguistic aspect like phonology, morphology, syntax, semantics and pragmatics.

\section{A. Phonological Level}

Comparison of phonemes of the Standard English and Nigerian English could be categorised as convergence and divergence in terms of similarities and differences. Where no difficulty is experienced in attaining the almost target language proficiency in English, it is described as a case of convergence or similarity. It is divergent when difficulty is 
experienced in the pronunciation of the English phonemes. This occurs because some sounds in English phonemic inventory are non-existent in the phonemics of such Nigerian languages. This, actually, is not unexpected since there are no two languages with the same phonological structure. Most interlinguistic intrusions occur at the phonological level, these are noticeable at the sound, stress, intonation and syllable units.

For example, Yoruba speaker of English will manifest the underlisted pronunciations:

The RP /z/ in zoo /zu:/ is substituted for /s/ as in /su:/

The RP/v/ in van /væn/ is substituted for /f/ as in /fæn/

The RP / $\mathfrak{g} /$ in church $/ \mathfrak{t} 3: \mathfrak{t} /$ is substituted for $/ \mathrm{f} /$ as in $/ \int \mathfrak{5}: \int /$. This realization is as a result of MT interference since the sound $/ \mathrm{z}, \mathrm{v}, \mathrm{g} /$ do not occur in Yoruba;

$/ \mathrm{h} /$ hardly features in Yoruba hence its occurrence in YE gives two different realisations-first, deletion at the wordinitial positions such as andsome for handsome, ouse for house, eadache for headache, and second, insertion borne out of hypercorrection like [hai] for eye, [ha:t] for art.

The absence of $/ \mathrm{h} /$ in Yoruba speech pattern may also be the justification for the choice of the indefinite article "an" in collocations such as: an holiday, an herbalist, an historian, etc.

\section{1. the specific features of IE pronunciation}

Igbo pronunciations of English have been greatly influenced by the attitude of Igbo to imitate other peoples' culture including the language habits. However, there is alternation between /1/ and /r/ found among some Igbo speakers from Anambra and Enugu States in some expressions like: *sullounded (for surrounded), *dangelous (for dangerous), *crinic (for clinic), *prug (for plug), *rocal (for local), *Cathoric (for catholic), *virrage (for village), *plamary (for primary), *play (for pray). The Igbos are also easily known when they pronounce /e/, the mid-short front vowel rather than /eI/, a diphthong, and $/ 1 /$ the voiced alveolar liquid, instead of $/ \mathrm{r} /$, the post-alveolar frictionless continuant consonant. The alternation between $/ \mathrm{l} /$ and $/ \mathrm{r} /$, noticeable among Igbo speakers of English, is always dramatized as a form of stigmatized accent peculiar of them.

Also, the production of the English phonemes /p/ and /f/ poses some difficulty to Hausa speakers of English. For instance, /f/ is replaced with /p/ in the word 'people' rendered as /fi:ful/ fifle instead of /pi:pul/. Hausa accent is often satirized for the switching which is prominent in the use of /p/ and /f/, and the replacement of /b/ with /v/. Examples are *dippiculty (for difficulty), *priend (for friend), *froblem (for problem), *pone (for phone), *bery good (for very good). These Hausa English examples result from mother-tongue intrusion. Whereas /p/ and /f/ are allophones in Hausa, the phoneme / $/$ / is non-existent in the Hausa phonology. These accents serve as ethnic group markers.

A typical Nigerian English speaker reduces the distinction in vowel quality between short and long vowels. This is linguistic nativization of Nigerian language vowels and consonants for English ones (Odumuh, 1987 and Jowitt, 2000). Non-native English speakers articulate the language segmentally and suprasegmentally. For instance,

/e/ is substituted for /ei/ as in day

$\mathrm{lo} /$ is substituted for $/ \mathrm{\partial u} /$ as in go

/a/ is substituted for /a:/ as in car

$/ \mathrm{u} /$ is substituted for $/ \mathrm{u}: /$ as in book

$/ \mathrm{t} /$ is substituted for $/ \Theta /$ as in thought

\section{2. syllable structure}

CV, notes Jakobson (1968) and Gimson (1980), represents the most primitive and without doubt historically the oldest of all syllable types, the only one which is general in all languages. Besides, it is the one which is learned by the child in language acquisition. Any other type other than this often generates complications as in how to determine the exact syllable boundaries. The syllable structure of many indigenous Nigerian languages is consonant-vowel (CV), hence the phonotactic constraint compels Igbo and Yoruba English users to insert epenthetic vowel to break consonant cluster. This insertion changes the original English pronunciation. The insertion of epenthetic vowels especially /u/ and /i/ are also used at word-final syllabic consonant in conformity to CV syllable structure (cited in Babarinde, 2015: 67).

\section{Yoruba}

card /káàdì/

glass /gíláàsì/

inch /ínínsi//

bread /búrédì/

alum /álóò̀mù/

\section{3. tone influence}

The stress patterns of Nigerian English unconsciously replaced by tone. This is because almost all the Nigerian indigenous languages are tone languages. This replacement of stress pattern of English with tone produces wrong pronunciations of stressed English words:

ma'dam $\longrightarrow$ màdáámú

o'ffice $\longrightarrow$ ófiìsì

re'cord $\longrightarrow$ rékọoòdù

On intonation, Odumuh (1987) and Kperogi (2007) had earlier observed that Nigerian languages are syllable-timed rather than stress-timed rhythm nature of English. According to them, syllable-timed rhythm is used by Nigerian 
English speaker with a reduced intonation. All these features distinguish the Nigerianism in Nigerian English as a distinct speech habit of Nigerian English speakers.

\section{B. Nigerianism Influence on the Grammatical Structure of Nigerian English}

The influence of ethnolinguistic experience of Nigerian speakers of English is also apparent at the word level. Such features like the introduction of culture-induced lexical items, back formation, semantic shift, different verb-preposition combinations, the omission of function words, semantic extension of L1 lexical items, retention of anaphoric pronoun in non-subject relativization and some Nigerian L1-induced grammatical structures among others. These are explained below:

\section{1. omission of function words 'the' and 'a/an'}

The grammatical error ignorantly committed by Nigerian English speaker is not unconnected with their strict application of the grammatical structure of sentence construction in Nigerian indigenous languages to the standard English. Analysis of data obtained from the respondents who were students of the University of Nigeria, Nsukka has shown that this error arising from the omission of definite and indefinite article is not limited to the uneducated folks. The situation can be illustrated with the following sentences obtained from the English of Hausa, Igbo, and Yoruba respondents. Examples here are sample representatives of what obtains in all the national language.
a. $\quad *$ We are in market.
'We are in the market.'
b. $\quad *$ I will like to be engineer. 'I will like to be an engineer.'
c. *I study at University of Nigeria, Nsukka. 'I study at the University of Nigeria, Nsukka.'
d. *I have lecture by 9am. 'I have a lecture by 9 am.'

The source of this form of grammatical deviation from standard English is cross-linguistic interference from Nigerian indigenous languages to English. The challenges of a Yoruba English user for instance is that of a little shift between the English articles 'the', 'a/an', and 'naa', 'kan' in Yoruba respectively. Although there is a shift, these articles, unlike in English, are not realized as pre-modification element in the Yoruba language. This means that náà (the), kan (a/an) are realized as qualifiers, as in:

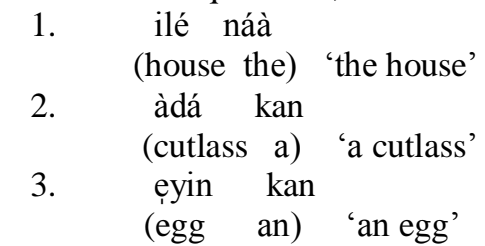

Given this structural difference, the Nigerian English bilinguals remain inconsistent by wrongly using the articles, or omit them, or include them sometime.

\section{2. misappropriation of ordinals and cardinals}

Ordinator 'one' is another feature of Nigerianism which can be traced to the Nigerian English. Ordinator is used in place of the indefinite article 'a', as in:
a. *He got one chair.
b. * One man is going.

The use of cardinal 'one' for ' $a$ ' arises from the confusion of 'one' with the indefinite article 'a/an'. The reason for this is not far-fetched. In Yoruba for example, an exponent 'kan' corresponds to 'one' and 'a/an' in English, as in:

a. Igo kan

(bottle one/a) 'one/a bottle'

b. Ile ifowopamo kan

(bank one/a) 'one/a bank'

The problem associated with the appropriate use of 'one' and the indefinite article 'a/an' predisposes the Nigerian user of standard English to translate and transfer the only available form in his/her mother tongue into English as seen above.

\section{3. redundant use of adjectives}

The perpetual redundant use of demonstrative and possessive adjectives that and my, our, your respectively is another feature of Nigerianism often displayed especially by the Yoruba English speakers while using Nigerian English.
a. *Give me that my book.
'Give me that book.' Or, 'Give me my book.'
b. *Where are those our books. 'Where are those oranges?' Or, 'Where are our oranges?'

\section{4. misapplication of pronoun}

The transfer of the pronoun àwon/won 'they' conventionally used as honorific pronoun in the Yoruba languages into English is another notable instance of Nigerianism peculiar to Yoruba English user. It is used generally used in the language as a pronoun for two or more persons, or an indefinite group of people in a context, or for an elderly individual. Examples are:
a. * They attended the meeting.
b. * They are calling you.
c. * They swept the room.
which could be, 'The principal attended the meeting.'
which could be, 'My father is calling you.'
which could be, 'The elder sister swept the room.'
They can as well still function as third person plural marker. 
Besides, reflexive pronouns such as themselves and ourselves are noticeable influence of indigenous languages on Nigerian English. These pronouns are used in place of each other, as in:

a. $\quad *$ Chima and I are looking at ourselves (each other)

b. $\quad *$ Immediately we see ourselves (one another), Kunle, Tunji and I began to play.

This could be the transfer of the corresponding intuition like ara wa or ara won which corresponds to ourselves/themselves, or one another/each other respectively in Yoruba, an indigenous language to English.

\section{5. the use of 'to-infinitive' and the improper use of phrasal verbs}

An examination of the data collected shows dropping of an infinitive to that usually precedes verbs. This is noticeable in the speech habit of highly educated Nigerians, and it cuts across all the ethnolinguistic divides of the Nigerian society.

*This will allow me attend a crucial meeting. 'This will allow me to attend a crucial meeting.'

The inappropriate use of prepositions also dotted Nigerianism use of the English language phrasal verbs.

a. *I wish to congratulate you for your promotion. (congratulate on)

b. *Let us discuss about the project. (discuss the project)

c. * She insists in doing it. (insist on)

\section{6. lexical features of Nigerianisms}

Semantic extension, semantic shift, and coinage are some noticeable lexical features in Nigerian English.

1). semantic extension

Semantic extension refers to the process through which one or more semantic senses within the same or another conceptual domain are added to a language. Semantic extension here implies the inclusion of meaning(s) to a given standard English word by Nigerian bilinguals.

a. It is at the tail end.

b. The meeting is scheduled for 9 pm in the night.

2). semantic change

This is a form of language shift regarding the creation of new words usage in which its modern meaning is different from its original usage. In other words, the central context of the word becomes marginalized.

a. The machine is not working. (machine for motor-cycle especially among Yoruba English user.

b. Get me some bottles of minerals. (minerals for soft drinks)

3). coinage

This is a manifestation of creative nature of language whereby new words are formed by Nigerian English bilinguals to express their culture-induced communicative needs that are non-existent the standard English. Nigerian English across different ethnolinguistic regions manifests use coinage as a productive word-formation process to express their thoughts.

a. She had a carryover in GNS 101. (She failed or referenced GNS 101.)

b. The man said he was caught up in go-slow. (traffic jam)

c. We are about to enter the motor at the park. (board the vehicle)

d. He is doing four-one-nine (advance-fee-fraud)

\section{CONCLUSION}

The data analysis has further justified the commonly held assertion that that there is no language that is self-sufficient to cater for all its communicative needs. Nigerians are very creative in their use of the English language, being a second and an official language, to express their need, feelings and desires. The extent of their creativity is made manifest in the way Nigerianism, that is, the influence of indigenous languages is apparent in their speech habit in their conscious effort to achieve relevance within the sociocultural environment. The cultural fact persists; the various linguistic and socio-cultural thoughts of Nigerians cannot be sufficiently expressed in the standard form of the English language where Nigerians do not have both the linguistic and communicative competence hence, the different lexical derivations, creativity and improvisation to adapt to the situation and context of usage of the language. Ogunsiji (2004) notes that though scholars are still inconclusive about the features of Nigerian English, but it is certain that there is Nigerian English with its own peculiar characteristics which are determined by the Nigerian socio-cultural environment. However, in line with the view of this paper, Kperogi (2007) observes that Nigerian English should not be seen as being a substandard variety of standard English. It should rather be seen as a legitimate national variety that has emerged out of our experiences as a post-colonial multilingual nation. It can therefore be taken as a Nigerian language since it provides another means for Nigerians to express their culture. Its pride of place in Nigerian context will remain unchallenged especially now that the so-called Nigerian English has been further reduced to a broken form known as Nigerian pidgin English or naija. It is time Nigerian government accords it all the necessary attention it deserves.

\section{REFERENCES}

[1] Adegbija, E. (2004). The language situation in Nigeria and a tentative language register. In E. Adegbija (Ed.). Multilingualism: A Nigerian case study. (pp. 37-47). Eritrea: Africa World Press Line.

[2] Adesanoye, F.A. (1973). A study of varieties of written English in Nigeria. A Ph.D Thesis, University of Ibadan. 
[3] Adetugbo, A. (1979a). Nigerian English phonology: Is there any standard? Lagos: Review of English Studies, ix, 64-84.

[4] Babajide, T. A. (2001). A systemic phonological study of Nigerian English. M.A. Dissertation. University of Ilorin.

[5] Babarinde, O. (2015). Knowledge of phonotactic constraints in Yoruba: A necessary tactic behaviour for linguistic competence in the language. Language Matters: Studies in the Languages of Africa. 46(1). 60-80.

[6] Bamgbose, A. (1982). Standard Nigerian English: Issues of identification. In B. B. Kachru (Ed.) World Englishes and applied linguistics, (pp. 91-111). Amsterdam: John Benjamins.

[7] Bamgbose, A. (1995). English in the Nigerian environment. In A. Bamgbose, A. Banjo \& P. Thomas (Eds.) New Englishes: A West African perspective, (pp. 9-26). Ibadan: Mosuro \& The British Council.

[8] Bamgbose, A. (1998). Torn between the norms: innovations in World Englishes. World Englishes, 17:1-14.

[9] Banjo, A. (1971). The standard Nigerian spoken English. Proceedings of the Eighth Congress of the West African Linguistic Society, Abidjan.

[10] Bennui, P. (2008). A study of L1 interference in the writing of Thai EFL Students. Malaysian Journal of ELT.

[11] Bobda, S. A. (1995). The phonology of Nigerian English and Camerounian English. In A. Bamgbose, A. Banjo, and P. Thomas (Eds.) New Englishes. A West African Perspective, (pp. 86-101). Ibadan: Mosuro.

[12] Ellis, R. (1997). Classroom interaction and its relation to second language learning. RELC Journal, 12(2), 87-105.

[13] Gimson, A.C. (1980). An introduction to the pronunciation of English. London: Edward Arnold.

[14] Grieve, J. (1966). A statistical analysis of regional variation in adverb position in a corpus of written standard American English. Corpus Linguistics and Linguistic Theory, 8(1), 39-72.

[15] Igboanusi, H. (2006). A comparative study of the pronunciation features of Igbo English and Yoruba English speakers of Nigeria. English Studies. 87(4), 490-497

[16] Jakobson, R. (1968). Child language aphasia and phonological universals. The Hague: Mouton de Gruyter.

[17] Jibril, M. (1986). Phonological variation in Nigerian English, In Ubahakwe, E. (Ed.). Varieties and Functions of English in Nigeria, 43-53. Ibadan: African Press.

[18] Jowitt, D. (1991). Nigerian English usage. An introduction. Ibadan: Longman.

[19] Jowitt, D. (2000). Patterns of Nigerian English intonation. English Worldwide 21(1). 63-80

[20] Jowitt, D.(2008). Standard Nigerian English: A re-examination. Journal of the Nigerian English Studies Association. 3. 1-18.

[21] Kachru, B.B. (1982). Models for non-native Englishes. In B. B. Kachru (Ed). The other tongue. (pp. 31-57). New Delhi: Oxford University Press.

[22] Kperogi, S. N. (2007). Spoken and written English in Nigeria. In Ubahakwe, E (Ed.) Varieties and functions of English in Nigeria. (pp. 10-11). Lagos: Lynx Press.

[23] Kridalaksana, H. (1985). Tata Bahasa Deskriptif Bahasa Indonesia: Sintaksis. Jakarta: Pusat Pembinaan dan Pengembangan Bahasa Departemen Pendidikan dan Kebudayaan.

[24] Odebunmi, O. (2006). English in Southern Nigeria. English Studies, 39. 97-110

[25] Odumuh, A. (1987). Nigerian English. Zaria: Ahmadu Bello University Press.

[26] Ogunsiji, R. (2004). Nigerian English phonology: Is there any standard? Lagos Review of English Studies. ix. 64-84.

[27] Salami, O. (1968). Diffusion and focusing: Phonological variation and social networks in Ile-Ife Nigeria. Language in Society, 20(2), 217-245.

[28] Weinreich, U. (1968). Languages in contact. The Hague: Mouton.

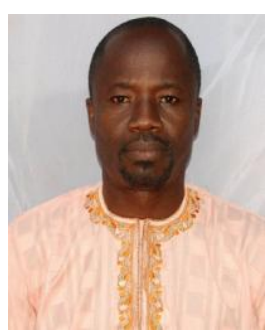

Olusanmi Olasunkanmi Babarinde was born in Gbongan Osun State on 22nd May, 1974. He had his Bachelor of Arts Degree at the University of Ilorin. He obtained M.A and PhD degrees in Linguistics at the University of Nigeria in 2006 and 2012 respectively. His area of specialization is phonology, morphology, and language documentation. He is a postdoctoral student in the Department of Linguistics and Nigerian Languages, University of Nigeria Nsukka. He has a number of scholarly publications to his credit. These include "Computer-assisted language instruction and language learning: Evidence from the English-learning Yoruba talking books 1-5. Language Matters: Studies in the Languages of Africa. 50(2), 100-111"; "Theme, diction and prosodic systems in Yoruba lullabies. International Research in Children's Literature, 12(1). 1833"; A constraint-based analysis of morphological processes in the Ibibio language. Journal of Language Teaching and Research, 11(2), 242-251.

His professional associations include Linguistic Association of Nigeria, Association for the Promotion of Yoruba Language and Culture, and Modern Language Association of Nigeria.

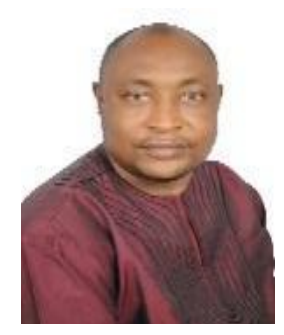

Ndubuisi Ogbonna Ahamefula was born at Isuochi, Abia State Nigeria on $22^{\text {nd }}$ August, 1970. He had his Bachelor of Arts Degree and Master of Arts Degree in Linguistics at the University of Nigeria, Nsukka. Ndubuisi is a doctoral student in the same University. He specializes in applied linguistics and sociolinguistics.

He has a number of publications to his credit including, Contrastive Analysis of consonantal phonemes and Phonotactics of Igbo and Ijo (I o n)". Journal of Linguistic Association of Nigeria (JOLAN), 21(2), 206-223. The Igbo Language Need Analysis of Non-Igbo in the University of Nigeria Postgraduate Students: Implication for Curriculum. Research on Humanities and Social Sciences. Vol.3 (14), 57-68.

Mr. Ahamefula is a member of Linguistic Association of Nigeria. 